\title{
Variations in lipoproteine-lipase activity in muscle and adipose tissues between preruminant and weaned calves
}

\author{
JF Hocquette ${ }^{1}$, T Olivecrona ${ }^{2}$
}

IINRA, Laboratoire Croissance et Métabolismes des Herbivores, Theix, 63122 St-Genès Champanelle, France ; 2Department of Medical Biochemistry and Biophysics, University of Umeoa, 90187, Sweden

In growing animals, nutrients are partitioned between various tissues, especially adipose and muscle tissues. Energy-yielding substrate partitioning is controlled by a complex interaction between substrate availability and metabolic activities of tissues. Marked changes occur at weaning in the pattern of nutrients available for energy utilization and storage. The rate-limiting step for delivery of long-chain fatty acids (LCFA) from triacylglycerol-rich lipoproteins is usually lipoprotein-lipase (LPL) activity, an enzyme produced by muscle and adipose tissues (AT). Since variations in key enzyme activities is indicative of the ability of a tissue to adapt metabolically, an investigation was undertaken to evaluate the influence of weaning on LPL activity in muscle and AT.

The experiment was conducted on two groups of seven preruminant or weaned Montbéliard calves. These latter were weaned at the age of 118 days. Protein, carbohydrates and fat provided $<20,>40$, and $35 \%$ of absorbed energy, respectively, for the first group. In contrast, protein, volatile fatty acids and tat provided $<25,65$ and $<8 \%$ of absorbed energy, respectively, for the second group. Net energy intake from birth onwards (740-760 Mcal), age (170 days) and empty body weight (194 kg) at slaughter were similar for the two groups so that, only the effects of changes in energyyielding substrates was studied. Protein and DNA contents and LPL activity were measured in subcutaneous (SCAT), omental (OAT) and perirenal (PAT) adipose tissues, heart $(\mathrm{H})$ and masseter (MA) (oxidative muscles). LPL activity was too low in other muscles to be measured accurately. After homogenization of tissues in detergent-containing buffer, LPL assay was performed at $25^{\circ} \mathrm{C}$ with Intralipid ${ }^{(B)}$ as substrate into which [3H]triolein has been incorporated (Chevreuil et al, 1993, Arterioscler Thromb, 13, 1391-1396). Isocitrate dehydrogenase (ICDH) and lactate dehydrogenase (LDH) activities were also measured in muscle tissues.
LDH and ICDH activities (characteristics of oxidative and glycolytic muscle metabolisms, respectively) were similar in muscles from preruminant and weaned calves except in MA. Indeed, ICDH activity (in nkat per $\mathrm{g}$ wet tissue) was $71 \%$ higher in ruminant calves $(P<0.001)$ which could be related to solid food chewing after weaning. LPL activity (in $\mathrm{mU}$ per $\mathrm{g}$ wet tissue) was $90 \%$ higher in MA from weaned calves than from preruminant calves $(P<0.05)$ which could be related to the higher oxidative metabolism of this particular muscle after weaning. In contrast, LPL activity tended to be lower in heart from weaned calves $(-22 \%$, $P<0.10)$. Results were similar when expressed per mg protein or per $\mu g$ DNA.

DNA and protein contents per $g$ wet tissue were higher in SCAT, OAT and PAT from weaned calves than from preruminant calves $\{+25$ to $+65 \%$ for DNA, $\mathrm{P}<0.05,+4$ to $+31 \%$ for protein, $P<0.10$ ) suggesting that cells of $A T$ were smaller after weaning. LPL activity (in $\mathrm{mU}$ per $g$ wet tissue) was lower in AT from weaned calves $(-58,-55$ and $-59 \%$ in SCAT, OAT and PAT respectively, $P<0.01)$. These differences were higher when the results were expressed per $\mu \mathrm{g}$ DNA ( -67 to $-70 \%, \mathrm{P}<0.01$ ) or per $\mathrm{mg}$ protein ( -58 to $-73 \%, \mathrm{P}<0.05)$.

Plasma insulin concentration tended to be lower in weaned calves $(-23 \%, P<0.12)$. This reduction might contribute to the decrease in LPL activity of AT after weaning.

In conclusion, our results suggest that, for the same net energy intake, the decrease in the dietary supply of fat and carbohydrates after weaning induced a decrease in LPL activity in $\mathrm{H}$ and AT. Our results also suggest that the lower LPL activity explains, at least in part, the reduced size of the cells in AT from weaned calves. Moreover, our data showed that LPL activity in muscle tissue was strongly related to the oxidative metabolism rate of muscle. Finally, it is suggested that a specific regulation of LPL activity in muscles and AT at weaning might favour LCFA uptake by some oxidative muscles (MA but not $\mathrm{H}$ ) for catabolism rather than by AT for fat deposition. 